\title{
The discovery of the circle of Willis as a result of using the scientific method in anatomical dissection
}

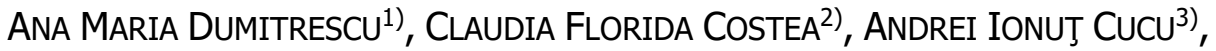

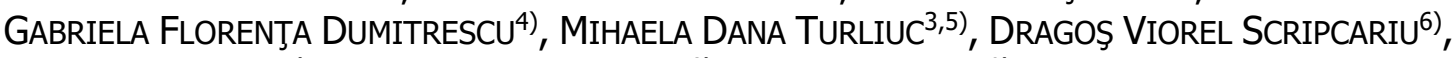 \\ MANUELA CiOCOIU ${ }^{7)}$, DANIELA MARIA TĂNASE ${ }^{8)}$, ŞERBAN TURLIUC ${ }^{9)}$, CAMELIA MARGARETA BOGDĂNICI ${ }^{2)}$, \\ SimONa Delia NiCOARĂ ${ }^{10)}$, ALEXANDRU CăRĂULEANU ${ }^{11)}$, SPERANTJA SCHMITZER ${ }^{12)}$, ANCA SAVA ${ }^{4,13)}$ \\ 1) PhD Student, Grigore T. Popa University of Medicine and Pharmacy, Iaşi, Romania \\ 2) Department of Ophthalmology, Faculty of Medicine, Grigore T. Popa University of Medicine and Pharmacy, Iaşi, Romania \\ 3) $2^{\text {nd }}$ Neurosurgery Clinic, Prof. Dr. Nicolae Oblu Emergency Clinical Hospital, Iaşi, Romania \\ 4) Laboratory of Pathology, Prof. Dr. Nicolae Oblu Emergency Clinical Hospital, Iaşi, Romania \\ 5) Department of Neurosurgery, Faculty of Medicine, Grigore T. Popa University of Medicine and Pharmacy, Iaşi, Romania \\ 6) Department of General Surgery, Faculty of Medicine, Grigore T. Popa University of Medicine and Pharmacy, Iaşi, Romania \\ 7) Department of Pathophysiology, Faculty of Medicine, Grigore T. Popa University of Medicine and Pharmacy, Iaşi, Romania \\ ${ }^{8)}$ Department of Internal Medicine, Faculty of Medicine, Grigore T. Popa University of Medicine and Pharmacy, Iaşi, Romania \\ 9) Department of Psychiatry, Faculty of Medicine, Grigore T. Popa University of Medicine and Pharmacy, Iaşi, Romania \\ 10) Department of Ophthalmology, Faculty of Medicine, Iuliu Haţieganu University of Medicine and Pharmacy, Cluj-Napoca, \\ Romania \\ ${ }^{11)}$ Department of Obstetrics and Gynecology, Faculty of Medicine, Grigore T. Popa University of Medicine and Pharmacy, Iaşi, \\ Romania \\ 12) Department of Ophthalmology, Faculty of Medicine, Carol Davila University of Medicine and Pharmacy, Bucharest, Romania \\ ${ }^{13)}$ Department of Anatomy, Faculty of Medicine, Grigore T. Popa University of Medicine and Pharmacy, Iaşi, Romania
}

\begin{abstract}
There are numerous articles on the discovery of this arterial polygon, its history being quite long, beginning with the Antiquity and up to the Modern Era. Making an analysis of the primary and secondary sources on this topic, the purpose of this article is to identify the significant moments of the discovery of this arterial polygon, which is an anatomical structure with great importance for neurologists and neurosurgeons. We will present the contributions to this topic from Renaissance and early Modern Era anatomists, such as Andreas Vesalius, Jean Fernel, Gabriel Fallopius, Giulio Cesare Casseri, Adriaan van den Spiegel, Johann Vesling, and Johann Jakob Wepfer von Schaffhausen. We also pointed out that the contribution of the famous British anatomist Sir Thomas Willis (1621-1675) was the most important one. He published De Cerebri Anatome, in 1664, in which he described the vascular arrangement laying at the base of the brain, accompanying it by the exquisite drawings of Christopher Wren. Thus, he demonstrated to the medical world that he had reached the greatest understanding of the structure and function of the circular arterial anastomosis. For this excellent discovery, his followers honored him by giving his name to this arterial circle.
\end{abstract}

Keywords: rete mirabile, anatomy, circle of Willis, De Cerebri Anatome.

\section{口 Introduction}

Thomas Willis (1621-1675), a physician and Professor of Natural Philosophy at Oxford in the mid- $17^{\text {th }}$ century, demonstrated with great precision both the structure and the function of one major anastomotic arterial system $[1,2]$. For this reason, the name of this structure is interchangeable, either as Willis' circle or as Willis' polygon, being one of the most famous eponymous structures in human anatomy.

Regarding its location within the body, this arterial circle lies at the base of the brain, creating an arterial anastomosis that ensures the constant irrigation with blood of this vital organ. This anastomotic structure received along time various nominations, such as the arterial circulus or circulus arteriosus cerebri, even though this is not actually a circle, but an anastomotic arterial polygon. Even though many researchers considered it as having a polygonal shape, they did not agree with the number of its sides, and described it as hexagonal [3], heptagonal [4], or nonagonal [5], and as such we can consider that naming it as "arterial polygon" seems to fit better.

\section{Aim}

There are numerous articles on the discovery of this arterial polygon, its history being quite long, beginning with the Antiquity and up to the Modern Era. Making an analysis of the primary and secondary sources on this topic, the purpose of this article is to identify the significant moments of the discovery of this arterial polygon, which

This is an open-access article distributed under the terms of a Creative Commons Attribution-NonCommercial-ShareAlike 4.0 International Public License, which permits unrestricted use, adaptation, distribution and reproduction in any medium, non-commercially, provided the new creations are licensed under identical terms as the original work and the original work is properly cited. 
is an anatomical structure with great importance for neurologists and neurosurgeons.

\section{ㅁ Rete mirabile and medicine in Antiquity}

The history of the cerebral blood circulation has its origins in the Greco-Roman Antiquity, when doctors knew quite a lot about the vessels at the base of the brain, but quite little about other parts of the nervous system.

By that time, there were two schools of philosophical thinking regarding the human body. Some had adopted the Aristotelian cardiocentric theory, according to which the heart controls sensation, thought and body movement. Others were the supporters of cephalocentrism, first introduced by Pythagoras and later supported by Plato, who indicated that the brain has the dominant role of controlling the body.

Even though along the time the first hypothesis has been proven to be erroneous, it helped to the discovery of the cardiovascular system as the Aristotelians interpreted brain blood vessels as transporters of the warm blood from the heart to the brain as this organ was seen as being far away from the center of the body and, as such, much cooler. Starting from these ideas, the Alexandrian School and then Galen believed that blood played a vital role in the human body.

On the other hand, there was the cephalocentric theory, conceived by the Greek philosopher Plato, which led to the understanding that this organ needed adequate blood intake because otherwise serious consequences could have occurred leading to the death of the person.

Rete mirabile, as a fine network of vessels originating from the internal carotid artery (ICA) and being located at the base of the animal brain, was discovered on dissections by the ancient physician Herophilus (335-280 BC) and described later by Galen, who is considered one of the founders of anatomy. Due to its location at the base of the brain, Galen brought in the idea that rete mirabile is the site where natural spirits, coming from the heart to the brain through the blood, are converted into animal spirits. Using almost entirely animal brains for his anatomical findings and studies, Galen has identified this admirable structure at the base of the bull's brain. Erroneously, he then extrapolated this discovery from animal to human dissections [3] and erroneously introduces this terminology into the human anatomy.

\section{ㅁ The denial of human rete mirabile in Renaissance}

In the following thirteens centuries, the Galenical authority took control over the anatomical studies, but during the Renaissance, when human dissections began to be approved, important anatomical aspects and notions of the arteries and veins, including those at the cerebral level, were acquired, so that a certain doubt about the inclusion of rete mirabile among the human structures was born. Without having a very good understanding of the physiology of the intracranial blood circulation, the Renaissance anatomists identified the vessels at the base of the brain during their dissections and saw that these vessels were quite different than those Galen had written about.

\section{Andreas Vesalius and his contributions}

Some authors consider that the great Renaissance anatomist Andreas Vesalius (1514-1564) could not distinguish the vein from the arteries especially because both types of vessels were somehow similar from a gross point of view. Moreover, cerebral vessels are thinner than those from other part of the body. For these reasons, he did not realize important contributions to the structure of the arterial circle even though he was a good observer and a careful dissector [6]. Catherine E. Storey \& Hans Pols consider that Vesalius was still under the great authority of Galen who did not recall such anastomoses at this level but the existence of rete mirabile [3].

However, Vesalius, an important figure of the University of Padua, performed numerous dissections on human corpses that were available for him due to the approval of the Senate of Venice. With these occasions, he demonstrated that the myth of the existence of Galen's rete mirabile in humans is completely erroneous (Figure 1). Vesalius's conclusion was firm: "There is no such structure that can be identified at the base of the human brain", and this statement was made known to everyone through Book VII of his excellent treatise De Humani Corporis Fabrica, printed in 1543 [7]. In addition, if we carefully look at Figure 16 of Book VII (Figure 2), we can see, along with the image of the pituitary gland, the drawing on its both sides of the "the sleeping arteries" (or what we now call ICAs), which were represented "as he had encountered in dissections". We identify in this graphical representation the anterior segment of the arterial circle and even a small part of its posterior portion [8]. In the Vesalius' illustration (Figure 2), the letters correspond to the following anatomical structures: $A$ - pituitary gland; $B$ - infundibulum; $C$ - carotid arteries, which continue with $F$ - possibly still the carotid artery, shown in duplicate on the right side, which is the presence of an anatomical variant; $H$ - may represent the segments $\mathrm{A} 1$ and $\mathrm{A} 2$ of the anterior cerebral artery (ACA); $G$ - middle cerebral artery (MCA), $D$ - possibly the posterior interconnecting artery.

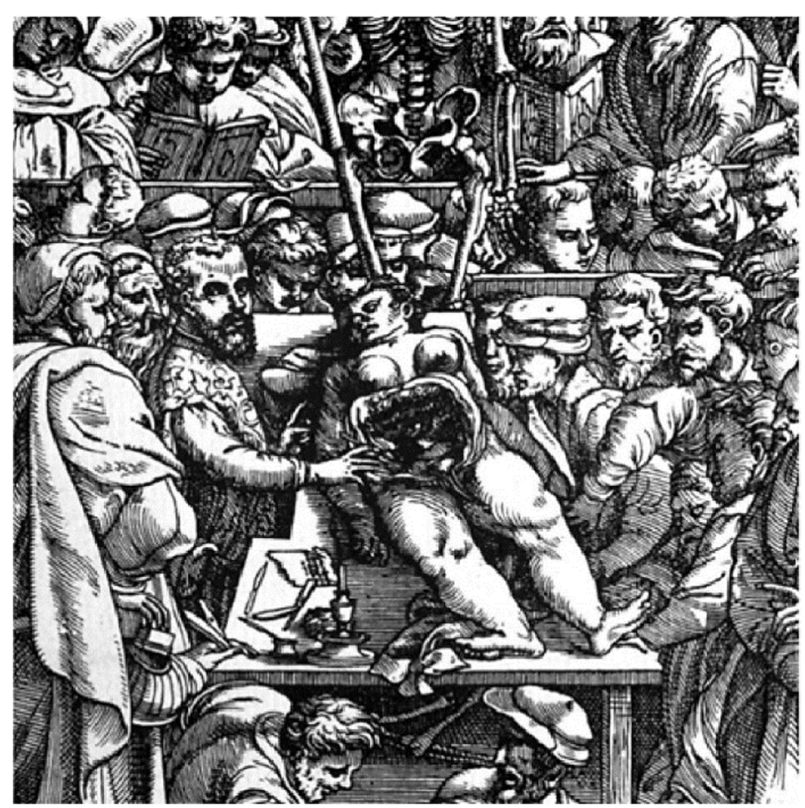

Figure 1 - Detail of the frontispiece of the anatomical treatise De Humani Corporis Fabrica representing the portrait of Andreas Vesalius dissecting the abdomen of a corpse (after Vesalius, 1543). 


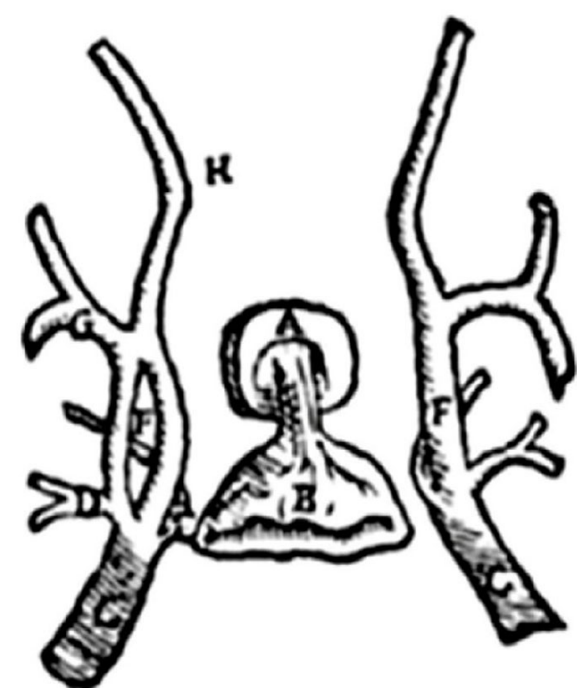

Figure 2 - Graphic representation of the pituitary and arterial vessels in Figure 16 of Vesalius' treatise De Humani Corporis Fabrica, in which only few arteries constituting the anterior part of the cerebral artery polygon can be identified (after Vesalius, 1543).

Therefore, despite the excellent anatomical illustrations of his treatise (Figure 1), possibly drawn by the painter Jan Stephan van Calcar (c. 1499-1546), Titian's student [9], there was not a correct description of the arterial circle of communicating vessels at the base of the brain. It is believed that the obvious errors in the distribution of arteries were related to the practice of dissecting the vessels from their place and then taking them out of the body, with the main purpose of spreading them on a sheet of paper. Afterwards, their bloody contour was taken for teaching and drawing purposes.

However, the significant contribution brought by Vesalius to the representation of the arteries from the base of the brain was the description of the anterior segment of the arterial polygon, thus opening the way for new research. In addition, from his assertion: "As these portions of the artery vary from dissector to dissector, we have drawn variants thereof" [8], we find a particularly important fact. Vesalius is the first one mentioning the anatomical variants of the arterial circle and even illustrated two of these: lack of anterior communicating artery (ACoA) and duplication of the ICA.

The demonstrations of Jean Fernel on the clinical significance of the arterial polygon

Since the $16^{\text {th }}$ century, a growing number of evidence has emerged that prove the Galenic statements to be wrong. One year after the publishing of De Humani Corporis Fabrica by Vesalius, in 1544, the French physician and philosopher Jean Fernel (1497-1558), also an opponent of Galen's teachings, presented a case of a man who died due to apoplexy after a cranial trauma. As he performed the autopsy, Fernel also discovered that at the base of the brain there was no rete mirabile as Galen had described in his treatises. In addition, Fernel was the one who showed that the death of a patient previously suffering stroke was due to a blood clot that obstructed the blood flow (considered to be vital spirits) through the arteries located at the base of the brain [3].

\section{Gabriel Fallopius was the first anatomist who described the arterial polygon, but an incomplete one}

Some authors credit Gabriel Fallopius or Fallopio (1523-1562) to be the first to describe the arterial circle, although incompletely. He was Vesalius' disciple and Professor of Anatomy and Botany at the University of Padua, as well. Although he did not make an illustration of the arterial circle in his text, Gabriel Fallopius presented, in Observationes Anatomicae (1561), an almost complete description of the arterial polygon [5]. Describing a union and then a division of the vertebral arteries, as well as the union of the internal branches of the carotid artery (corresponding to ACA), Fallopius was the first to correctly recognize the ramifications of the basilar artery and nearly two-thirds of the posterior communicating artery (PCoA), but he considered that the last artery was only indirectly connected to ICA via a small arteries network [10]. As such, he did not recognize the significance of PCoA for the completion of the functional vascular loop.

\section{$\square$ The new spirit brought by the Modern Age}

The Modern Era begins with the Baroque, a dominant reality in Europe during the period of the most intense conflict between Aristotelian ideas, which had become official for the scholastic spirit, and, at the opposite pole, the knowledge born from Platonic metaphysics. The Baroque was the era when Plato's philosophy was imposed as a counterweight to the authority that Aristotle had enjoyed until then. The great lesson of Platonism was that the true reality had to be sought by the intellect and not by the senses [11].

At the end of the $16^{\text {th }}$ century, anatomy underwent a renewal based on the numerous knowledge gained through dissections that had become a habit, especially after the opening of anatomical theaters throughout Europe, which offered this opportunity [12].

Becoming a true science towards the end of the $16^{\text {th }}$ century, anatomy was also seen as an art. If the structure and function of the organs of the body began to take shape, the place where the soul and all mental processes could be located was still under discussion, because, since Antiquity, there has been a fierce controversy on this issue. The Aristotelian model survived until the $17^{\text {th }}$ century, probably because the authority of the magistrate was unwavering. On the other hand, Plato had supported the encephalocentric model because he believed in the supremacy of the brain over the rest of the body. He believed that in the brain is the divine and immortal part of the soul, which commands and controls the rest of the body [13]. However, the direct consequence of all these philosophical controversies was a more accurate activity towards the anatomical investigation.

\section{Giulio Cesare Casseri' s magnificent legacy}

Also known as Julius Casserius, Giulio Casserio, or Giulio Casserio (1552-1616), Giulio Cesare Casseri from Piacenza, studied the anatomy with Professor Fabricius ab Aquapendente at the University of Padua. Taking over his master's position, in 1604, at the Department of Surgery 
and Anatomy, he started working on an anatomical treatise that he wanted fully illustrated, and, for that purpose, he hired Odoardo Fialetti (1573-1638), an Italian painter, disciple of Tintoretto.

Before dying, in 1616, Casserio failed to print what he wanted to call Theatrum Anatomicum and left a legacy of 86 spectacular anatomical drawings made by Fialetti, but no explanatory text [14].

\section{The first description of the sides of the arterial polygon made by Adriaan van den Spiegel}

Adriaan van den Spiegel, also known as Adrianus Spigelius (1578-1625), was a Flemish anatomist who was born in Brussels. Following Casserius at the Department of Anatomy and Surgery of the University of Padua, he wrote a non-illustrated anatomical treatise that remained unpublished during his lifetime. In his will, Spigelius named the German physician Daniel Bucretius as the successor who should print his work. After Spigelius' death, Bucretius began to publish Spiegelius' treatise and, in order to illustrate it, he obtained from Casserius' heirs only 78 of the 86 original anatomical plates made by Fialetti. To complete the series, he ordered 20 more illustrations to the same painter, being engraved in copper by Valesio. Thus, in 1627 , the best work of the $17^{\text {th }}$ century on human anatomy appeared posthumously, with numerous subsequent editions, entitled De Humani Corporis Fabrica Libri X, Tabulis XCIIX. This book contained detailed descriptions of the anatomical structures and impressively beautiful illustrations accompanying them. The book borrowed the title from De Humani Corporis Fabrica, written by Spigelius's compatriot, Andreas Vesalius, but was conceived by Daniel Bucretius, its editor, as an update of the medical anatomical thinking, as a result of the progress achieved over the past 70 years that separated the two famous treatises [10].

In Liber $X$, there is an illustration which depicts the arterial circle at the base of the brain (Figure 3), being among the drawings that were made under the careful command of Casserius [11]. It is recognized as the first drawing of the arterial circle at the base of the brain, printed as Tabulae $X$, and each of its components is marked with letters for a better identification.

The translation of the text, as well as the drawing shows that he had correctly identified all the sides of the arterial polygon, especially on its right side. The left side of the polygon is not symmetrically drawn compared to the right one, because PCoA seems to be formed by the union of two thinner vessels, just as it was explained in the text. Considered a morphological variant of the arterial polygon, this anatomical drawing was identified on the deceased where the autopsy was performed.

Alfred Meyer \& Raymond Hierons also noticed the discrepancy between the illustration and the explanatory text, and they consider that while the PCoA is clearly visible on the right side, on the opposite side it seems to be formed by the union of two thin vessels, just as explained in the text. But it should be considered, as well, that the text was not written by Casserio, but by Bucretius [10].

By analyzing Tabulae $X$ and its explanatory text (Figure 3), we found that the letter $K$ represent the largest branch of the ICA, i.e., MCA. Moreover, Casserio wrote as following: "from it (ICA) two other arteries originate: first, b.b. internal (ACA) that later joins with the corresponding branch on the opposite side near C.... The branches of the cervical artery (called vertebral by Spigelius) ... enter together the cranial cavity through the first large hole of the occiput and are soon reunited in S, under the beginning of the bulb that is in it (in the foramen magnum); thus, they go together (forming the basilar artery) just below the base of the brain on the median line. When they reach the so-called pineal gland of the cuneiform bone, in the $\mathrm{T}$ point, they divide into two branches, one left and one right (noted by G.G. and representing Posterior Cerebral Artery), which divide again into many small branches (h.h.) (one of them being Posterior Communicating Artery), which will unite with the small branches of the Internal Carotid Artery (f.f.) (to form the choroid plexus)" [10]. Casserio's contribution to "the heptagon discovered later by Willis" was recognized by Giuseppe Sterzi, his biographer (1909-1910) [4].

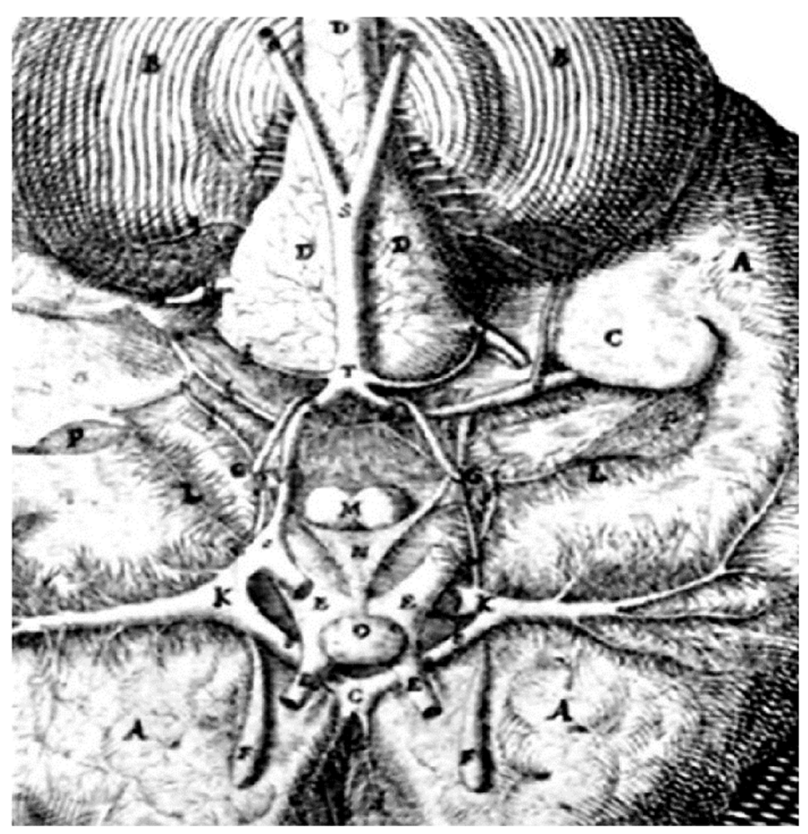

Figure 3 - Illustration called Tabulae X, included in the treatise Tabulae Anatomicae LXXIIX, to represent the arterial polygon at the base of the brain (after Casserius, 1632).

\section{Incomplete illustrations of the arterial polygon by Johann Vesling}

Another renowned name that can be associated with the discovery of the arterial circle at the base of the brain is Johann Vesling (1595-1649), also known as Wesling, as he started his career path in Germany, or by his Latin name, Veslingus, when he became Professor of Anatomy and Surgery in Padua. He published the first edition of Syntagma Anatomicum in Frankfurt in 1614. The paper did not contain illustrations or explanations of the arterial circle. Other editions published later, in 1647 and 1651, represented an almost complete arterial circle [5].

The legend of the illustration called Figurae II (Figure 4) mentioned that the letters $\mathrm{CC}$ indicated "the big branch of the internal carotid artery that joins the OO vertebral artery; ... OO is the common branch of the vertebral artery that has been split up after union to join the carotid artery, 
CC. The two arteries are branching together forming the rete mirabile, at the level of the sella turcica of the cuneiform bone (the sphenoid bone). Also, the letters PPPP indicate the small arterial branches (ramuli arteriarum minuti), which constitute the rete mirabile" [15].

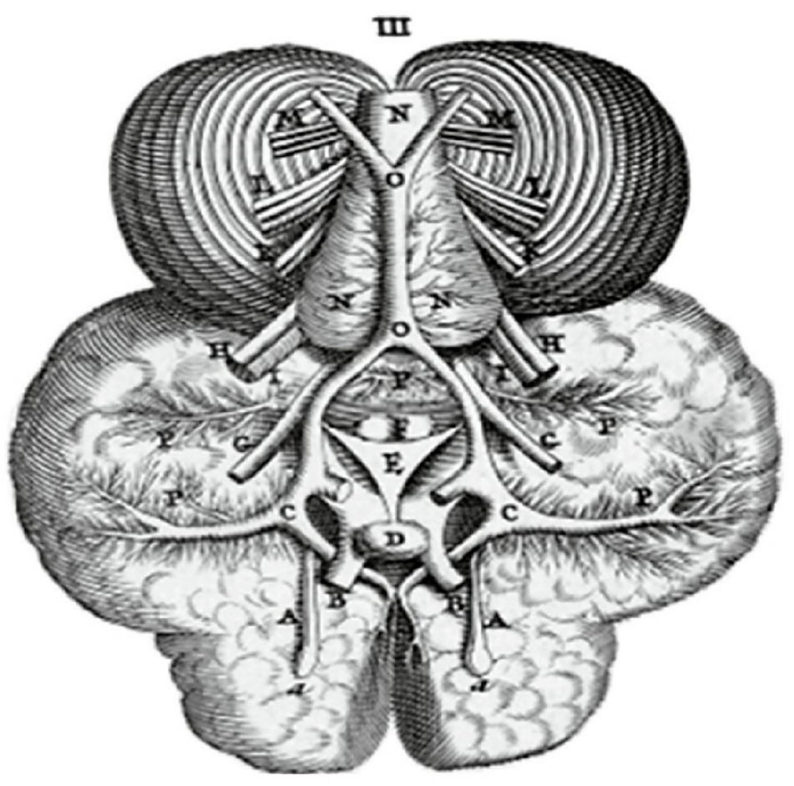

Figure 4 - Illustration called Figurae III, included in Syntagma Anatomicum, printed in 1647, represents an incomplete arterial polygon (after Veslingus, 1651).

If we look carefully at Figurae II, we can notice that the representation of the arterial circle is fairly correct. Even though the arteries were not marked with letters, the ACAs are correctly illustrated, being noticeable their union through the ACoA, although their joining is not explained in the text. The PCoA appears as a direct continuation of the basilar artery after its partition, without indicating the existence of a posterior cerebral artery (PCA). What we now call the middle cerebral artery (MCA) it was drawn as a vessel that penetrated the Sylvian fissure, but this is not marked. The short branches that were drawn as originating mainly from PCoA around the pituitary stem correspond to the supposed place of the rete mirabile, which Vesling failed to discard. The letter $P$ indicates the network of small arteries derived from the Sylvian artery and other vessels that have a tract beneath the temporal lobe surface [15].

\section{Was Johann Jakob Wepfer von Schaffhausen the real discoverer of the "arterial polygon" before Willis?}

Anatomists, such as Wepfer \& Willis, used their talents in the $17^{\text {th }}$ century to describe the arteries at the base of the brain as a precursor exercise for the important followup studies in the coming centuries. Meyer \& Hieron believe that Johann Jakob Wepfer von Schaffhausen (1620-1695) from Switzerland was the real discoverer of the "arterial circle" six years before Thomas Willis would make this acquisition [10]. In his Observationes anatomicae ex cadaveribus eorum quos sustulit apoplexia (1658), Wepfer von Schaffhausen realized a magnificent description of the arterial circle at the base of the brain, although with no attached illustrations. Wepfer presented in a very accurate manner the carotid artery trace, then that of its earlier branch, which, he said, goes to the crista galli to which it attaches, and "at the point where the brain splits in two parts, the right branch joins the left one, then it separates again ... as they move forward they give more branches to the convulsions on the face of the brain fissure ... the posterior branch of the carotid artery travels a little on its tract and then joins the vertebral artery that has divided again into two" [10]. Wepfer's description clearly reveals that he was aware of the anastomoses that make up the circle, as he took note of all the important ramifications coming from the carotid and vertebral arteries, focusing in a complex manner on their anastomoses as well [5].

Thomas Willis became recognized as the first anatomist to illustrate the complete and symmetrical picture of the arterial polygon

The European anatomists of the $17^{\text {th }}$ century adhered to the Platonic ideas that the brain, being the place that housed the intellect, should be considered the main organ of the human beings. The same thing happened in the anatomical research from England, where there seemed to be a struggle between Aristotelian and Platonic ideas. At the beginning of the $17^{\text {th }}$ century, William Harvey (1578-1657) had paid special attention to the study of the heart and published in 1628 a treatise on the subject, in the second half of the same century, Thomas Willis (16211675) was concerned with further research of the brain.

However, Willis took over the description of the blood flow published by William Harvey, in 1628, as well as Casserius', Vesling's and Wepfer's anatomical works, but brought new contributions to them. Willis published De Cerebri Anatome, in 1664, this being the most complete and correct description of the nervous system at that time [3]. The work represents not only his personal effort and involvement, but that of a group of researchers, working together at The Oxford Experimental Philosophy Club to conduct various chemical, physical, and anatomical experiments. Later, this association became the famous Royal Society of London [16].

Sir Thomas Willis published De Cerebri Anatome in 1664 (Figure 5), in which he described the vascular arrangement laying at the base of the brain, accompanying it by the exquisite drawings of Christopher Wren. Thus, he demonstrated to the medical world that he had reached the greatest understanding of the structure and function of the circular arterial anastomosis. At their turn, his followers honored him by giving his name to this arterial circle located at the base of the brain. Since its discovery, the "circle of Willis" is one of the most renowned eponymous structures in human anatomy, which marked the transition between medieval and modern notions on the morphology and function of this anatomical entity [5].

During his neuroanatomical observations and interpretations, Dr. Thomas Willis was assisted by these natural philosophers as these researchers called themselves (Figure 5). The physician and anatomist Dr. Richard Lower (1631-1691) was one of Willis' closest associate, who, after his work to brain anatomy, went to study the anatomy and physiology of the heart and lungs. Five years later, he published his own book on blood circulation, entitled Tractatus de Corde (1669), and gave acknowledgement to Willis [17]. 


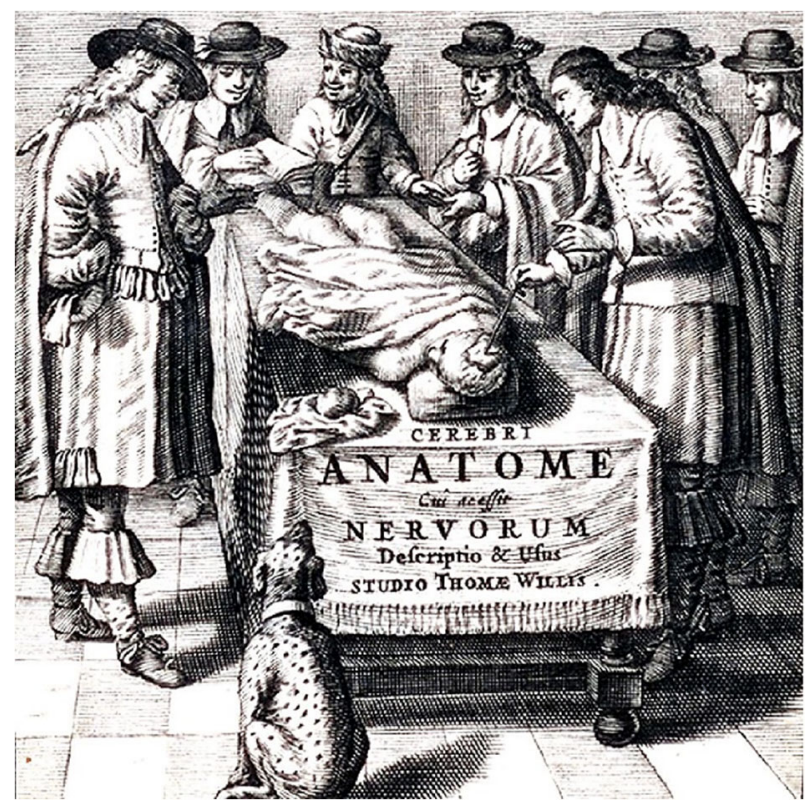

Figure 5 - The cover of the book De Cerebri Anatome, edition 1665/1666, published in Amsterdam, shows Thomas Willis' associates, among whom Christopher Wren is noted with the sketchbook and Lower pointing towards the dissection of the head. The drawing included, of course, the author of the treatise, Thomas Willis, positioned to the left, while the others looked at him (after Willis, 1665/1666).

Another assistant was the physician Sir Thomas Millington (1628-1704), a close friend of Willis', who was his successor as a Professor at the Department of Natural History, in 1675 . He became very active at the Royal College of Physicians and opened a private cabinet in London, being very active later on [17].

Willis had another important contributor, called Sir Christopher Wren. He later became the great architect of London, who effectively took part in the accomplishment of De Cerebri Anatome by drawing many of the illustrations (Figure 6) "for this study to be as accurate as possible" [17]. Wren previously performed numerous physiological and anatomical experiments himself and even developed a technique for intravenous injections to animals. So, even though he was an architect, we can say that he was very familiar with the field of anatomy. Thus, he knew how to inject Chinese ink and other colored substances into the carotid arteries [18], which has led to an accurate highlight of the collateral circulation of the brain and identified the physiological and pathological significance of the arterial circle located at the base of the brain.

As the brain has a soft consistency and it degrades rapidly, it can only be stored for a short period of time. By injecting alcohol into autopsied brains [19], Willis and his team not only introduced a method that would underpin the histopathological processing of nervous tissue of over two centuries later, but at the time this method allowed preserving the brains and the vessels at their base for a long time, so that the anatomical details could be drawn by the artist.

While dissecting many corpses, Willis and his collaborators have been astonished to see that there is something "rare and singular" at the base of the brain, namely that there is an anastomosis of arteries with arteries, not arteries with veins. Thus, "the Carotid Arteries of one side, in many, are united with the Carotids of the other side; besides the Vertebrals of either side among themselves, and are also inoculated into the posterior branches of the Carotids before united. The joinings together of the Carotids, in most living Creatures, are made about the Base of the Skull under the Dura Mater..." [20].

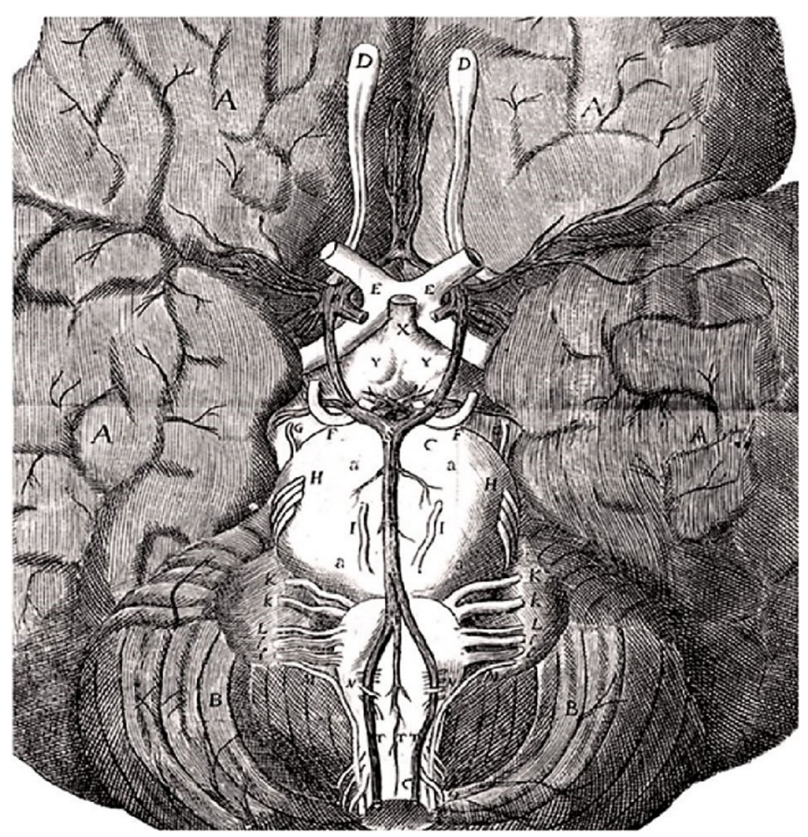

Figure 6 - Illustration of the complete and classic arterial circle located at the base of the brain, made by Christopher Wren in Willis's treatise, De Cerebri Anatome (after Willis, 1665/1666).

What becomes perhaps more important than this accurate description of the arterial circle is that Willis correlated its anatomy with physiology and clinics. He suggested that this anastomotic arterial network located at the base of the brain was designed to maintain cerebral blood irrigation, regardless the obstruction of any of the ICAs [18]. For practical purposes, he also gave clinical examples of the usefulness of this circle. He presented two of his cases whom he made an autopsy and pointed out the fact that in case of the obstruction of the ICA on one side the blood could come from the other ICA: "I once open the dead carcass of one wasted away, in which the right arteries, both the Carotid and the Vertebral, within the skull, were become bony and impervious, and did shut for the blood from that side, notwithstanding the sick person was not troubled with the astonishing disease (apoplexy)" [21].

However, Willis was the first anatomist publishing a drawing of this arterial structure and also he was the first who pointed out the function of this anatomical entity as an anastomotic circle ("a manifold way") that could maintain the blood flow inside the brain: "if by chance one or two should be stopped there might easily be found another passage instead of them, and for example, the carotids of one side being obstructed, the vessels of the other side might provide for either province so that if both carotids should be stopped, the offices of each might be supplied through the vertebrals" [22]. But the term "circle of Willis" was introduced in the anatomy terminology only 100 years later by Albrecht von Haller (1708-1777) and then in an anatomical text, Bibliotheca Anatomica 
(1774-1776). This author mentioned that Thomas Willis discovered many structures that belong to the nervous system, underlining that he rejected the existence of rete mirabile and presented the anastomosis of anterior branches of the carotid artery, structure that he calls the "circle of Willis", revealing that Wepfer mentioned earlier this anastomosis (rete mirabile rejicit ..., anastomosis ramorum anterium carotidum, circulum qui dicitur Willisii etsi horum pustrema Wepferus nuper dixerat) [23].

\section{ㅁ Conclusions}

It has been a gradual and hard work coming from several famous anatomists and artists along time in order to correctly describe, illustrate and recognize the sides of the arterial polygon located at the base of the brain. But Thomas Willis is the one who gave the neurologists, neurosurgeons, and anatomists the full picture of the arterial polygon located at the base of the brain, bringing observational, illustrative, and experimental evidence on this anatomical structure. Thus, the famous British anatomist should receive all the merits for this great discovery by giving his name to this particular structure, "the arterial circle of Willis".

\section{Conflict of interests}

The authors declare that they have no conflict of interests.

\section{References}

[1] Üstün Ç. Dr. Thomas Willis' famous eponym: the circle of Willis. Turk J Med Sci, 2004, 34(4):271-274. https://journals.tubitak. gov.tr/medical/issues/sag-04-34-4/sag-34-4-9-0402-10.pdf

[2] Lo WB, Ellis $H$. The circle before Willis: a historical accoun of the intracranial anastomosis. Neurosurg, 2010, 66(1):7-18 discussion 17-18. https://doi.org/10.1227/01.NEU.00003620 02.63241.A5 PMID: 19935436

[3] Storey CE, Pols H. Section 4: Dysfunctions of the nervous system - Chapter 27: A history of cerebrovascular disease. In: Finger S, Boller F, Tyler KL (eds). Vol. 95: History of Neurology. Handbook of Clinical Neurology Series [Aminoff MJ, Boller F, Swaab DF (eds)]. Elsevier, Edinburgh-New York, 2009, 403. https://doi.org/10.1016/S0072-9752(08)02127-1

[4] Sterzi G. Giulio Casseri anatomico e chirurgo (1552 c.-1616) Istituto Veneto di Arti Grafiche, Venezia, 1909, 122.

[5] Wolpert SM. The circle of Willis. AJNR Am J Neuroradiol, 1997, 18(6):1033-1034. PMID: 9194429

[6] Lanska D. The evolution of Vesalius's perspective on Galen's Anatomy. Hist Med, 2015, 2(1):13-26. https://doi.org/10.17 720/2409-5834.v2.1.2015.02I

[7] Vesalius A. De Humani Corporis Fabrica Libri Septem. Johannes Oporinus, Basel, 1555, 771.
[8] Vesalius A, Saunders JB de CM, O'Malley CD. The illustrations from the works of Andreas Vesalius of Brussels. A discussion of the plates, and a biographical sketch of Vesalius with annotations and translations by J.B. de C.M. Saunders and Charles D. O'Malley. Vol. 56, World Publishing Company, 1973, 194.

[9] Finger S. Origins of neuroscience: a history of explorations into brain function. Oxford University Press, New York, 1994, 21.

[10] Meyer A, Hierons R. Observations on the history of the 'circle of Willis'. Med Hist, 1962, 6(2):119-130. https://doi.org/10. 1017/s0025727300027095 PMID: 14473085 PMCID: PMC 1034698

[11] Dumitrescu M. L'Homme baroque. In: Dima T, Chiriac C (eds). Imaginaire honorifique. Hommage à Maryvonne Perrot. Ed. Terra Nostra, laşi, 2015, 271-292.

[12] Dumitrescu M. Theatrum Anatomicum and the baroque vision on death. The European Proceedings of Social \& Behavioural Sciences (EpSBS), Future Academy, 2016, 317-322. https:// doi.org/10.15405/epsbs.2016.09.41

[13] Dumitrescu M. Geneza barocă a filosofiei moderne. Ed. Sedcom Libris, Iaşi, 2016, 494.

[14] Casserius G. Tabulae anatomicae LXXIIX, omnes novae nec ante hac visae. Daniel Bucretius $X X$ quae deerant supplevit \& omnium explicationes additit. Impensis \& coelo Matthaei Meriani, Francofurti, 1632.

[15] Veslingus I. Syntagma anatomicum: locis plurimis auctum, emendatum, novisque iconibus diligenter exornatum. Secunda editio ab extrema auctoris manu. Typis Pauli Frambotti Bibliopolae, Patavii, 1651, 182-195.

[16] Lega BC. An essay concerning human understanding: how the Cerebri Anatome of Thomas Willis influenced John Locke. Neurosurgery, 2006, 58(3):567-576. https://doi.org/10.1227/ 01.NEU.0000197489.17675.C6 PMID: 16528199

[17] Donaldson IML. Cerebri Anatome: Thomas Willis and his circle. J R Coll Physicians Edinb, 2010, 40(3):277-279. https://doi. org/10.4997/jrcpe.2010.318 PMID: 20973440

[18] Arráez-Aybar LA, Navia-Álvarez P, Fuentes-Redondo T, Bueno-López JL. Thomas Willis, a pioneer in translational research in anatomy (on the $350^{\text {th }}$ anniversary of Cerebri Anatome). J Anat, 2015, 226(3):289-300. https://doi.org/10. 1111/joa.12273 PMID: 25688933 PMCID: PMC4337668

[19] van Gijn J, Gijselhart JP. [Willis and his circle]. Ned Tijdschr Geneeskd, 2012, 156(12):A4653. PMID: 22436528

[20] Willis T. The anatomy of the brain and the nerves [Feindel $\mathrm{W}$ (ed). Facsimile of the English edition by Samuel Pordage. 1681]. Vol. II, McGill University Press, Montreal, 1965, 82.

[21] Storey CE, Pols H. Section 4: Dysfunctions of the nervous system - Chapter 27: A history of cerebrovascular disease. In: Finger S, Boller F, Tyler KL (eds). Vol. 95: History of Neurology. Handbook of Clinical Neurology Series [Aminoff MJ, Boller F, Swaab DF (eds)]. Elsevier, Edinburgh-New York, 2009, 404. https://doi.org/10.1016/S0072-9752(08)02127-1

[22] Rose FC. History of British neurology. Imperial College Press, London, 2012, 37.

[23] von Haller A. Bibliotheca anatomica: qua scripta ad anatomen et physiologiam facientia a rerum initiis recensentur. Tomus I, Orell, Gessner, Fuessli, et Socc., Tiguri, 1774, 476.

\section{Corresponding authors}

Claudia Florida Costea, Associate Professor, MD, PhD, Department of Ophthalmology, Faculty of Medicine, Grigore T. Popa University of Medicine and Pharmacy, 16 University Street, 700115 laşi, Romania; Phone +40744972 648, e-mail: costea10@yahoo.com

Andrei lonuţ Cucu, MD, PhD Student, $2^{\text {nd }}$ Neurosurgery Clinic, Prof. Dr. Nicolae Oblu Emergency Clinical Hospital, 2 Ateneului Street, 700309 laşi, Romania; Phone +40748-378 468, e-mail: andreiucucu@yahoo.com 